\title{
Acute Adrenal Insufficiency as the Primary Manifestation of Extrapulmonary Tuberculosis: A Case Report
}

\author{
Herman Trianto, Nurria Betty, Laksmi Sasiarini, Rulli Rosandi, Putu Arsana, Djoko Soeatmadji, Achmad Rudijanto
}

Endocrinology, Metabolic Disease and Diabetes Division, Internal Medicine Department

Brawijaya University - Saiful Anwar General Hospital, Malang, Indonesia

\begin{abstract}
Acute adrenal insufficiency (AI) is a life-threatening condition. While Addison's disease (AD) is rare, in developing countries, tuberculosis (TB) still remains as the primary cause in 7 to $20 \%$ of cases. Urinary TB is also the third most common form of extrapulmonary disease. We report a case of 37 -year-old male who presented with weakness, anorexia, weight loss, dysuria, flank pain and low grade fever. Examination revealed hypotension, hyperpigmentation, hyponatremia, hypoglycemia and low serum cortisol. He was diagnosed to have adrenal crisis due to Addison's disease and extrapulmonary TB manifesting as urinary tract infection (UTI). He was treated with corticosteroids and anti-TB medications. Urologic reconstructive surgery was subsequently planned..
\end{abstract}

Key words: Addison's disease, acute adrenal insufficiency, serum cortisol, urinary symptoms, tuberculosis

\section{INTRODUCTION}

Addison's disease (AD), or primary adrenocortical failure, was first described by Thomas Addison in 1855 following his observations in 6 patients with adrenal tuberculosis..$^{1-3}$ Since then, the most commonly identified cause of adrenal failure has been bilateral adrenal destruction due to Mycobacterium tuberculosis infection. Recent studies also indicate that urinary TB is the third most common form of extrapulmonary disease, after peripheral lymphadenopathy. . $^{4}$

Tuberculosis continues to be a public health problem, as it is the most common worldwide cause of mortality from infectious disease, with an estimated global incidence of 8 to 10 million per year. Failure to treat initial pulmonary tuberculosis itself may lead to catastrophic outcomes such as peritonitis, lymphadenitis, orchitis and other urogenital disease and adrenal insufficiency, among other manifestations of extrapulmonary tuberculosis. Diagnosing extrapulmonary tuberculosis can also be challenging due to poor access to disseminated lesions, low rates of bacteriological positivity accounting only for a quarter of overall cases, paucibacillary lesions often resulting to negative smear results, and the absence of pathognomonic histopathologic findings. As such, the diagnostic approach to $\mathrm{AD}$ and urinary $\mathrm{TB}$ is difficult, especially in a resource-limited area. ${ }^{8-10}$

eISSN 2308-118x

Printed in the Philippines

Copyright (C) 2016 by the JAFES

Received: September 14, 2015. Accepted: April 25, 2016.

http://dx.doi.org/10.15605/jafes.031.01.11
Studies on Addison's disease and genitourinary TB in non-HIV patients are scarce, as these conditions are rare and probably underdiagnosed. We report the case of a 37-year-old male with chronic fever, weight loss, skin hyperpigmentation, hypoglycemia and hyponatremia due to Addison's Disease secondary to tuberculosis in Malang, Indonesia.

\section{CASE}

A 37-year-old male presented with a chief complaint of generalized weakness for 4 months, progressing to inability to stand independently on the day prior to admission. In the last 6 months, he noted dry cough, urinary urgency, dysuria, hematuria, right flank pain, decrease in appetite and hyperpigmentation of the skin. Two months prior to admission, he experienced low grade fever, more often observed at night. During the previous week, he began having nausea and started vomiting residual food 2 to 3 times a day, amounting to 50 to $100 \mathrm{~mL}$ each episode. He also noted passage of 100 to $200 \mathrm{~mL}$ of watery, non-bloody and non-mucoid stool once to twice a day, accompanied by loss of appetite and cold sweats. He noted weight loss of approximately $16 \mathrm{~kg}$ in the last 4 months.

He was diagnosed with a lung infection necessitating thoracentesis 20 years ago. He was declared as "cured" and

Corresponding author: Herman Bagus Trianto, $M D$

Supervisor, Consultant of Endocrinology and Metabolic Disease Division

Department of Internal Medicine

Faculty of Medicine Brawijaya University - dr. Saiful Anwar General Hospital

Jl. Jaksa Agung Suprapto no.2, Malang, Indonesia, 65111

Tel. No: $+62341-351445$

Fax. No: $+62341-351445$

Correspondence mail: drhermanbagustrianto@yahoo.com 
never received anti-TB medications. In the ensuing years, he often experienced weakness and needed hospitalization for sudden episodes of unconciousness. He denied any contact with TB patients, and had no other chronic or congenital diseases. He smoked 12 cigarettes per day for 20 years, but stopped 1 year ago when he felt unwell.

On examination, the patient looked ill and agitated, with a Glasgow Coma Scale of 15. He was hypotensive (blood pressure 70/50), tachycardic (pulse rate 106 beats/minute), tachypneic (respiratory rate 26 cycles/minute) and afebrile (axillary temperature $37 \mathrm{oC}$ ), with a body mass index of $15 \mathrm{~kg} / \mathrm{m} 2$ (body weight $39 \mathrm{~kg}$, height $163 \mathrm{~cm}$ ). We found hyperpigmentation of the skin and mucous membranes, pale palpebral conjunctivae, multiple left lateral cervical lymphadenopathy, and suprapubic and right flank tenderness (Figure 1). The other findings were within normal limits.
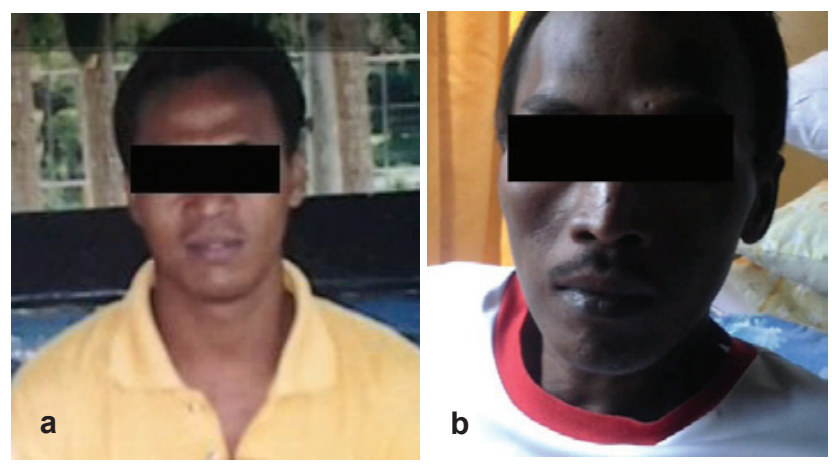

Figure 1. Comparison of the patient's appearance before his illness in 2013 (a) and during the time of examination in 2015 (b), showing marked skin hyperpigmentation.

Laboratory results showed anemia (hemoglobin 7.80 $\mathrm{g} / \mathrm{dL}$, hematocrit $21.40 \%$ ), normal leucocyte count $(6,000 / \mu \mathrm{L}$, differential counting 3/0/48/30/19, normal range: $0-4,0-1,51-67,25-33,2-5)$ and normal platelet count $(339,000 / \mu L)$. Further workup of anemia revealed hypochromic cells with anysocytosis on peripheral blood smear, serum iron $20 \mu \mathrm{g} / \mathrm{dL}$, total iron binding capacity $108 \mu \mathrm{g} / \mathrm{dL}$ and iron saturation $22 \%$. He had hypoglycemia which improved after correction (random blood sugar $45 \mathrm{mg} / \mathrm{dL}$ to $104 \mathrm{mg} / \mathrm{dL}$ ), azotemia (serum creatinine $1.25 \mathrm{mg} / \mathrm{dL})$, hypoalbuminemia $(2.3 \mathrm{~g} / \mathrm{dL})$ and hyponatremia $(119 \mathrm{mmol} / \mathrm{L})$. Serum cortisol serum at $0800 \mathrm{H}$ was low at $0.23 \mu \mathrm{g} / \mathrm{dL}$ (Table 1). Human immunodeficiency virus- ELISA was negative. Fecal analysis showed no abnormal result. Electrocardiogram revealed sinus tachycardia (heart rate 106 beats/minute).

Ultrasonography of the neck revealed left perijugular lymphadenopathy. Plain chest and apicolordotic radiographs revealed moderate pulmonary TB (Figure 2). Urinalysis revealed albuminuria, pyuria, hematuria and bacteriuria (Table 1). Staining for acid-fast bacilli (AFB) was negative in sputum samples, and positive $(+)$ for urine specimen. Urine culture showed no bacterial growth. Abdominal ultrasound revealed bilateral grade

\begin{tabular}{|c|c|c|}
\hline Variable & Result & Reference range \\
\hline Haemoglobin, g/dL & 7.8 & $11.4-15.1$ \\
\hline Platelet count, $\times 10^{9} / \mathrm{L}$ & 339 & $142-424$ \\
\hline White blood cell count, $\times 10^{9} / \mathrm{L}$ & 6.0 & $4.7-11.3$ \\
\hline Neutrophil, \% & 48 & $51-67$ \\
\hline Lymphocyte, \% & 30 & $25-33$ \\
\hline Monocyte, \% & 19 & $2-5$ \\
\hline Eosinophil, \% & 3 & $0-4$ \\
\hline Basophil, \% & 0 & $0-1$ \\
\hline Serum iron, $\mu \mathrm{g} / \mathrm{dL}$ & 20 & $49-151$ \\
\hline Total iron-binding capacity, $\mu \mathrm{g} / \mathrm{dL}$ & 108 & $250-350$ \\
\hline Iron saturation, $\%$ & 22 & $16-45$ \\
\hline Random blood sugar, mg/dL & 45 & $<200$ \\
\hline Blood urea nitrogen, mg/dL & 24.8 & $16.6-48.5$ \\
\hline Creatinine, $\mathrm{mg} / \mathrm{dL}$ & 1.25 & $<1.2$ \\
\hline Albumin, $\mathrm{g} / \mathrm{dL}$ & 2.3 & $3.5-5.5$ \\
\hline Aspartate transaminase, U/L & 43 & $0-32$ \\
\hline Alanine transaminase, $\mathrm{U} / \mathrm{L}$ & 22 & $0-33$ \\
\hline Sodium, mmol/L & 119 & $136-145$ \\
\hline Potassium, $\mathrm{mmol} / \mathrm{L}$ & 3.88 & $3.5-5$ \\
\hline Chloride, mmol/L & 98 & $98-106$ \\
\hline \multicolumn{3}{|l|}{ Arterial blood gas ${ }^{a}$} \\
\hline $\mathrm{pH}$ & 7.47 & $7.32-7.45$ \\
\hline $\mathrm{pCO}_{2}, \mathrm{mmHg}$ & 20.1 & $35-45$ \\
\hline $\mathrm{pO}_{2}, \mathrm{mmHg}$ & 116.5 & $80-100$ \\
\hline $\mathrm{HCO}_{3}, \mathrm{mmol} / \mathrm{L}$ & 14.9 & $21-28$ \\
\hline Base excess, $\mathrm{mmol} / \mathrm{L}$ & -9.1 & $(-3)-(+3)$ \\
\hline Oxygen saturation, \% & 99 & $95-100$ \\
\hline \multicolumn{3}{|l|}{ Urinalysis } \\
\hline Albumin & +1 & Negative \\
\hline Leucocyte, cells/high power field & +3 (533 cell/hpf) & Negative $(\leq 5 \mathrm{cell} / \mathrm{hpf})$ \\
\hline Erythrocyte, cells/high power field & +2 (217 cell/hpf) & Negative $(\leq 3$ cell/hpf) \\
\hline Bacteria, $\times 10^{3} / \mathrm{mL}$ & $160 \times 10^{3}$ & $<93 \times 10^{3}$ \\
\hline Serum cortisol, $0800 \mathrm{H}(\mu \mathrm{g} / \mathrm{dL})$ & 0.23 & $3.09-16.66$ \\
\hline
\end{tabular}

II to III hydronephrosis and chronic cystitis. This was consistent with subsequent findings in the intravenous urogram, which showed bilateral grade III hydroureteronephrosis due to obstruction at the distal ureters and contracted urinary bladder. However, histopathology result of urine cytology showed non specific chronic inflammation. Computerized tomography (CT) of the abdomen showed left adrenal gland hypoplasia, multiple cysts on the right adrenal gland, grade III to IV right hydronephrosis, grade II left hydronephrosis, chronic ureteritis and cystitis (Figure 3).

The patient was assessed to have adrenal crisis, Addison's disease secondary to tuberculosis infection, urinary TB with bilateral hydroureteronephrosis, pulmonary TB with moderate lesion, anemia of chronic disease, and hypoalbuminemia. In the acute setting, he was treated with dexamethasone $5 \mathrm{mg}$ intravenously four times daily, and maintained on two intravenous peripheral lines containing maintenance IVF D10\% on one, and IVF $\mathrm{NaCl} 3 \%$ on the other. D40\% was given with each episode of hypoglycemia, and fluid challenge with $\mathrm{NaCl} 0.9 \%$ following hypotension. Other treatments included ranitidine $50 \mathrm{mg}$ intravenously two times daily, metoclopramide $10 \mathrm{mg}$ intravenously three times daily and ceftriaxone $1 \mathrm{~g}$ intravenously two times daily. Packed red blood cells and albumin 20\% transfusions were also given. Fludrocortisone was not available in our hospital. 

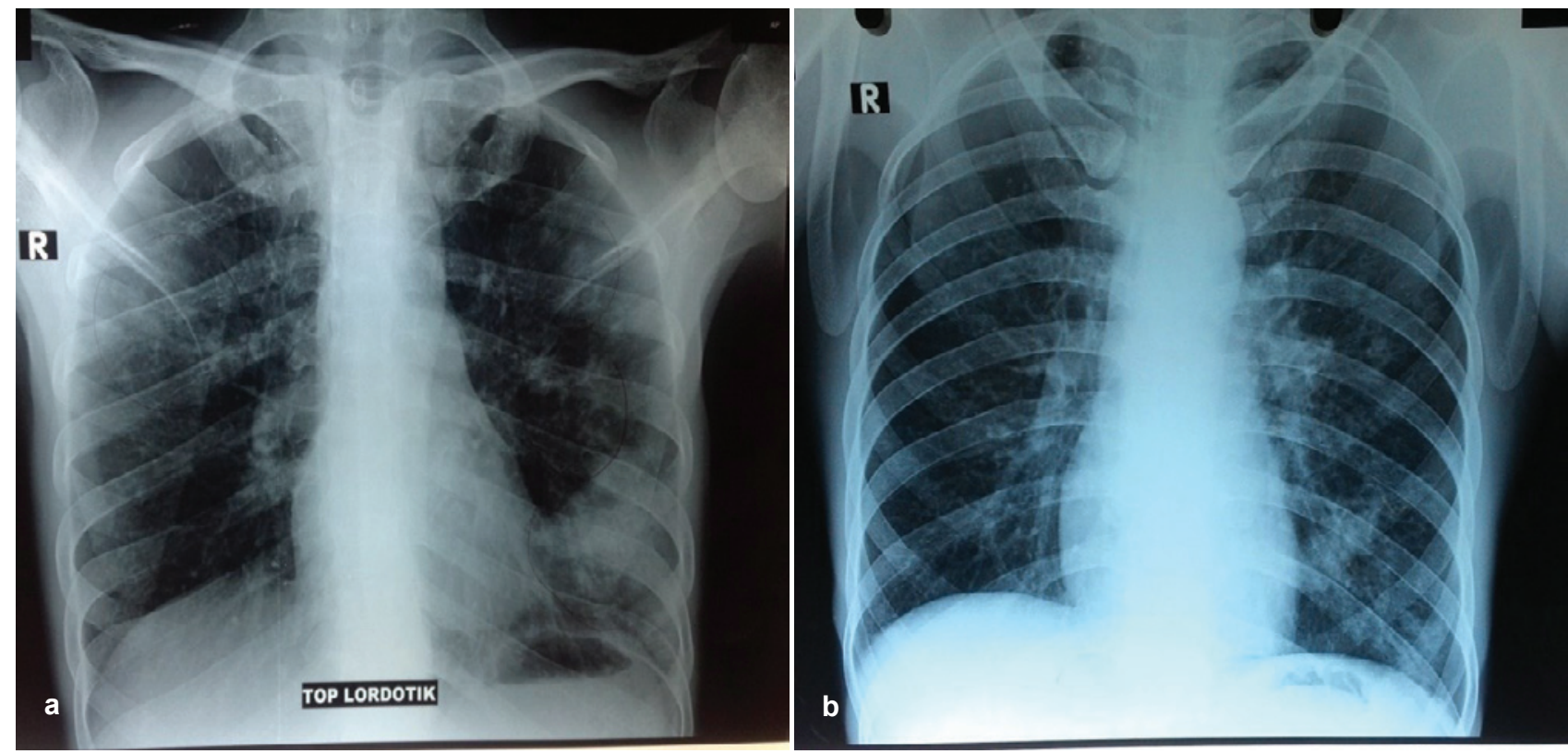

Figure 2. Chest radiographs (a) apicolordotic view revealed fibrotic infiltrates and calcifications on the upper right and lower left lung fields. (b) improvement after 2 weeks of antituberculosis treatment.

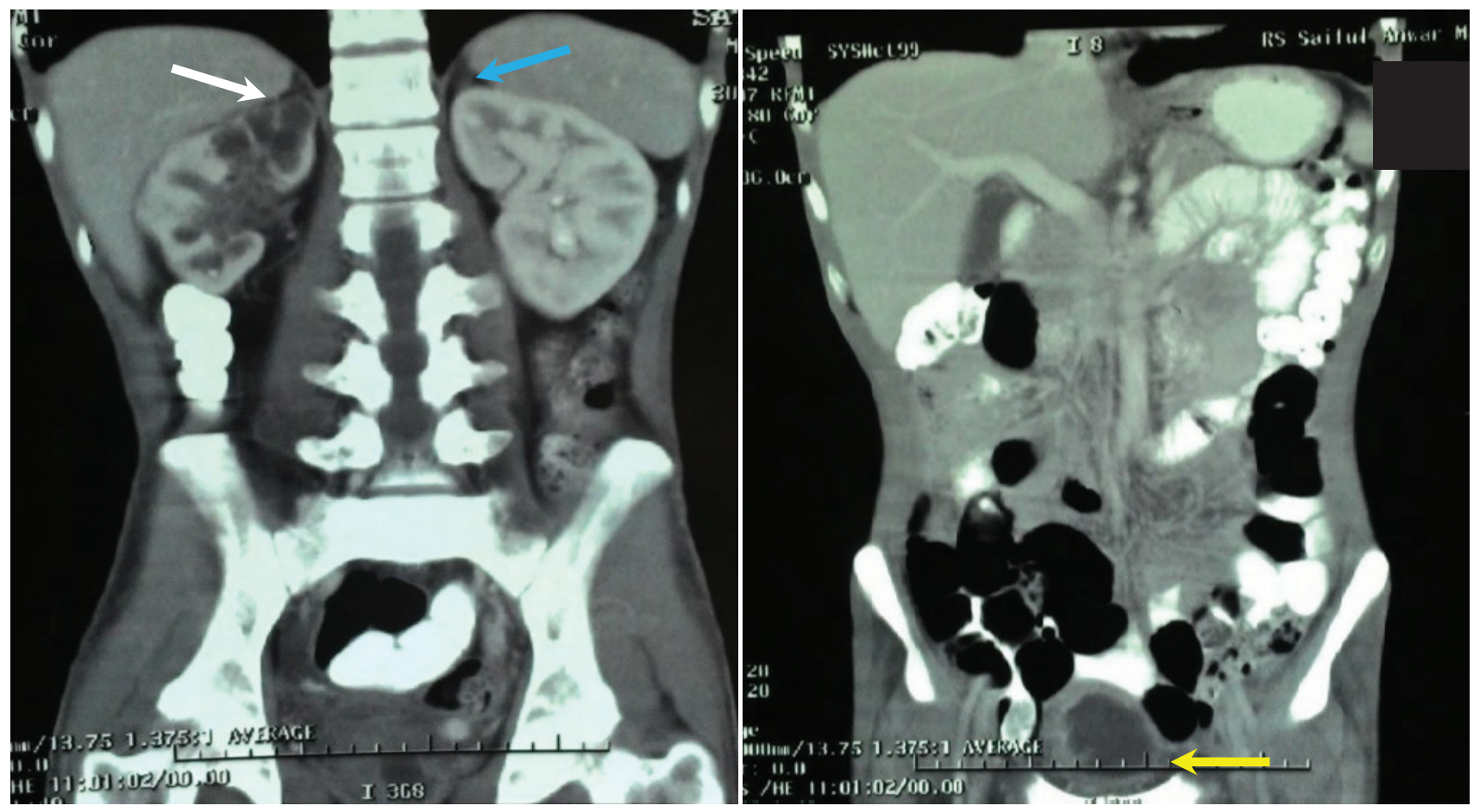

Figure 3. CT scan of the abdomen on coronal view showed a right adrenal gland measuring $3.3 \mathrm{~cm} \times 2.6 \mathrm{~cm}$ with multiple cysts (white arrow), a hypoplastic left adrenal gland measuring $1.4 \mathrm{~cm} \times 0.9 \mathrm{~cm}$ (normal value $4 \mathrm{~cm} \times 2 \mathrm{~cm})($ blue arrow), right hydronephrosis grade III to IV, left hydronephrosis grade II, chronic ureterithis and cystitis (yellow arrow).

After serum cortisol data became available, intravenous steroid was continued and later tapered to low dose oral dexamethasone $1 \mathrm{mg}$ once daily with the resolution of acute adrenal insufficiency. With chest X-ray, urine AFB and adrenal CT scan results supporting tuberculosis as the cause of the chronic lung infection, complicated UTI and Addison's disease, first category anti-TB medications (2 months of rifampicin, isoniazid, pyrazinamide, ethambutol followed by 7 months of rifampicin and isoniazid, or 2RHZE + 7RH) were given. The patient was discharged with instructions to maintain prednisone $5 \mathrm{mg}$ once daily, calcium lactate and vitamin D supplementation, anti-TB medications and vitamin B6, and to plan urologic surgery to release the urinary tract obstruction to prevent progression of chronic kidney disease. Subsequently, he never had any recurrence of weakness. Chest radiographs, electrolytes and glucose also improved. 


\section{DISCUSSION}

Addison's disease is a rare disorder with an estimated prevalence of approximately 120 individuals in one million. ${ }^{11}$ Tuberculosis is a common cause, accounting for 7 to $20 \%$ of cases. In developing countries, tuberculosis still remains the main cause of Addison's disease..$^{3,11,12}$ Infection, including $\mathrm{TB}$, should always be considered in males and in the elderly. ${ }^{3}$ Lam and Lo found that the five most common locations of extrapulmonary TB were the liver, spleen, kidneys, adrenal glands and bones. ${ }^{6}$ They reported that adrenal tuberculosis is found in $6 \%$ of patients with active tuberculosis. The adrenal glands were the only organs involved in active TB in $25 \%$ of cases, and bilateral involvement was seen in 69\%. Nomura and colleagues observed that $93 \%$ of the patients with adrenal tuberculosis had previously suffered from extra-adrenal $\mathrm{TB}$, mostly of the lung and pleura. ${ }^{10}$ As a young adult male living in a developing country with a history of lung infection, our patient matched the profile described in the epidemology of extrapulmonary tuberculosis.

Depending on the acuteness of the hormonal deficit and the presence of concurrent illness, symptoms may present acutely in adrenal crisis, or insidiously. Our patient developed nonspecific but progressive symptoms of fatigue, weakness, weight loss, anorexia, nausea and vomiting and diarrhea, which may have delayed consult and subsequent diagnosis. He finally presented with hypotension leading to shock accompanied by hypoglycemia, which were classic signs of adrenal crisis.9,12,15,16 Physical examination revealed cutaneous and mucosal hyperpigmentation, emaciation and hypotension. Routine laboratory findings revealed hyponatremia, azotemia and hypoglycemia. ${ }^{17-21}$

The diagnosis is usually made based on typical symptoms, and by documenting low serum cortisol, low concentration of urinary cortisol and its metabolites in the presence of elevated plasma ACTH. Biochemical findings are confirmed by a poor cortisol response to synthetic ACTH (tetracosactrin, $250 \mu \mathrm{g}$ intramuscularly or intravenously) given at $0900 \mathrm{H}$, with serum cortisol determinations measured at 0,30 and 60 minutes after administration. ${ }^{3}$ Plasma ACTH, rapid ACTH stimulation test and serum aldosterone were not available in our hospital. The diagnosis of primary adrenocortical insufficiency was based on clinical signs, symptoms, low serum cortisol, and the CT scan findings of hypoplasia and multiple cysts on the adrenal glands. The presence of hyperpigmentation suggested that adrenocortical insufficiency was due to a primary adrenal gland abnormality, in contrast to secondary causes (pituitary and hypothalamus), as low serum cortisol induces pituitary secretion of melanocyte-stimulating hormone (MSH) and ACTH. Abdominal CT scan findings on the adrenals, along with evidence of pulmonary and extrapulmonary tuberculosis, supported TB infection as the cause of Addison's disease. ${ }^{16}$

TB of the adrenal glands may be seen on CT scan imaging as bilateral enlargement on active infection, followed by atrophy and calcification on remote infection. We think our patient had remote infection in both adrenal glands, despite the absence of calcification. Calcification is observed in longstanding TB infection, with incidence on CT imaging varying from 40 to $59 \%$. Adrenal cysts have been reported to be caused by Echinococcus species. However, since Echinococcus infection is rare in Indonesia, and the patient's clinical appearance and fecal analysis did not support the evidence of infection, we concluded that TB was the main cause of adrenal insufficiency in our patient. $3,12,16-18$

Tuberculosis of the adrenal glands leads to inflammation, necrosis and destruction of adrenal cortical tissue. ${ }^{10}$ Adrenal tuberculosis results from hematogenous or lymphatic spread of primary tubercle bacilli infection elsewhere in the body. ${ }^{15}$ This is the reason for the more common finding of bilateral rather than unilateral involvement in TB infection. ${ }^{7,9,12}$ To date, the distinct tropism of tubercle bacilli with respect to the adrenal glands remains unknown.

In most cases, extra-adrenal TB is usually evident, but may be clinically latent. ${ }^{15}$ Nomura and colleagues described that in patients with tuberculous Addison's disease, the ensuing period from the precedent nonadrenal $\mathrm{TB}$ to the onset of $\mathrm{AD}$ ranges from 0 to 50 years, with a mean of $31.9 \pm 14.9$ years. ${ }^{10}$ Adrenal autoantibodies are usually absent in adrenal TB. ${ }^{15}$ It was found that only $7.1 \%$ patients with tuberculous AD had positive adrenal autoantibodies. ${ }^{15}$

The aims of treatment are to replace the deficient hormones and treat any reversible causes of adrenal disease. ${ }^{13}$ Despite the considerable capacity for regeneration of the adrenal cortex, $\mathrm{AD}$ due to tuberculosis is generally regarded as irreversible. ${ }^{6}$ Although recovery is sometimes possible after appropriate anti-TB therapy, only a few patients with adrenal TB have been shown to have recovered adrenal function. ${ }^{3}$ This recovery may be dependent upon the amount of residual viable adrenal tissue at the time of diagnosis, and on the adequacy of anti-TB therapy. However, patients usually have to maintain hormone replacement. ${ }^{11,15}$ Kelestimur suggested that recovery from adrenal insufficiency is not possible in patients with $\mathrm{AD}$ due to remote tuberculosis in which the adrenal glands are atrophic and calcified. ${ }^{19}$ Anti-TB medications may not be required if there is adrenal atrophy. However, if the adrenal glands are enlarged, anti-TB medications may be needed. ${ }^{19}$

Glucocorticoid replacement in chronic adrenal insufficiency involves the use of hydrocortisone 15 to 30 
$\mathrm{mg} /$ day orally or its equivalent (oral prednisone 5.0 to 7.5 $\mathrm{mg}$ /day or dexamethasone 0.75 to $1.25 \mathrm{mg} /$ day). In the acute setting, hydrocortisone 50 to $100 \mathrm{mg}$ or dexamethasone $4 \mathrm{mg}$ intravenously every 4 to 8 hours can be given until stabilization of the patient's condition. ${ }^{3}$ The aim of treatment with fludrocortisone in chronic adrenal insufficiency is to achieve normal sodium homeostasis and normal blood pressure. Over-treatment may result in hypertension and edema. ${ }^{3}$ Additional adrenal androgen replacement can be added, particularly if the patient has poor quality of life. DHEA may improve self-esteem, mood, fatigue scores, and libido, particularly in women. ${ }^{3}$ We did not have fludrocortisone or hydrocortisone in our hospital, thus the use of dexamethasone $5 \mathrm{mg}$ intravenously at the nearest converted dose once daily in the morning to mimic the physiologic peak. Correction of hyponatremia and hypoglycemia was stopped right after steroid coverage was given, with note of clinical and biochemical improvement. Dexamethasone was then tapered to $1 \mathrm{mg}$ orally, and then shifted to prednisone 5 mg once daily along with anti-TB medications.

Following anti-TB therapy, worsening of the patient's condition was anticipated due to the effect of rifampicin on cortisol metabolism. Many reports also describe the occurrence of adrenal insufficiency after the administration of rifampicin. Rifampicin facilitates the clearance of many drugs from the blood, including various glucocorticoids, via the induction of cytochrome CYP3A4, which metabolizes glucocorticoids in the liver. ${ }^{5}$ We monitored the patient closely during antituberculosis drug administration because of these effects.

Our patient was also had upper and lower urinary tract infections, based on history, physical findings and urinalysis. He received ceftriaxone as empirical treatment. Following urine tests indicating negative bacterial culture and positive AFB smear, urinary TB infection was considered as the cause of complicated UTI. Treatment of urinary tuberculosis includes antituberculosis treatment with rifampicin, isoniazid, pyrazinamide and ethambutol for 9 months; corticosteroid to reduce mucosal inflammation and relieve symptoms; and surgical intervention. About 55\% of genitourinary TB cases require surgery. Since the imaging findings revealed bilateral hydroureteronephrosis and chronic cystitis, urologic surgery was planned for obstruction release, drainage of pus, evacuation of calculi, augmentation of the urinary bladder and reconstruction of the upper and lower urinary tracts to prevent the progression of CKD. ${ }^{18,20}$

\section{CONCLUSION}

We reported a 37-year-old male with acute adrenal insufficiency and complicated UTI caused by tuberculosis. This report highlights the importance of prompt, adequate and complete treatment of pulmonary tuberculosis, as the likelihood of progression to extrapulmonary infection is very high. In this case, involvement of the adrenal glands and the kidneys led to a life-threatening condition of adrenal crisis and chronic kidney disease. Because of its significant impact on healthcare resources, our case underscores the importance of adequate provision of resources needed to conduct full implementation of programs for the treatment and eradication of of tuberculosis.

\section{Ethical Consideration}

Patient consent form has been procured prior to the case report study.

\section{Statement of Authorship}

All authors have given approval to the final version submitted.

\section{Conflict of Interest}

All the authors have declared no conflict of interest to the work carried out in this paper.

\section{Funding Source}

None.

\section{References}

1. Addison T. On the constitutional and local effects of disease of the supra-renal capsules. Medical History. 1969;13(2):195-202. http://dx.doi.org/10.1017/S0025727300014290.

2. Patnaik MM, Deshpande AK. Diagnosis -Addison's disease secondary to tuberculosis of the adrenal glands. Clin Med Res. 2008; 6(1):29. http://dx.doi.org/10.3121/cmr.2007.754a.

3. Brooke AM, Monson JP. Addison's disease. Medicine. 2009;37(8):4169. http://dx.doi.org/10.1016/j.mpmed.2009.05.006.

4. Guttman PH. Addison's disease: A statistical analysis of 566 cases and study of the pathology. Arch Path. 1930;10:742-85.

5. Kinjo T, Higuchi D, Oshiro Y, Nakamatsu Y, Fujita K, Nakamoto K, et al. Addison's disease due to tuberculosis that required differentiation from SIADH. J Infect Chemother. 2009;15(4):239-42. http://dx.doi.org/ 10.1007/s10156-009-0690-Z.

6. Lam KY, Lo CY. A critical examination of adrenal tuberculosis and a 28-year autopsy. Clin Endocrinol (Oxf). 2001;54(5):633-9. http://10.1046/j.1365-2265.2001.01266.x.

7. Ma ES, Yang ZG, Li Y, Guo YK, Deng YP, Zhang XC. Tuberculous Addison's disease: Morphological and quantitative evaluation with multidetector-row CT. Eur J Radiol. 2007;62(3):352-8. http://dx.doi.org/10.1016/j.ejrad.2006.12.012.

8. Yokoyama T, Toda R, Kimura Y, Mikagi M, Aizawa H. Addison's disease induced by miliary tuberculosis and the administration of rifampicin. Inter Med. 2009;48(15):1297-300. http://doi.org/10.2169/ internalmedicine.48.1974.

9. Zhang XC, Yang ZG, Li $Y$, Min PQ, Guo $Y K$, Deng $Y P$, et al. Addison's disease due to adrenal tuberculosis: MRI features. Abdom Imaging. 2008;33(6):689-94. http://doi.org/10.1007/s00261-007-9352-8.

10. Nomura K, Demura H, Saruta T. Addison's disease in Japan: Characteristics and changes revealed in a nationwide survey. Intern Med. 1994;33(10):602-6. http://doi.org/10.2169/internalmedicine.33.602.

11. Bhatia E, Jain SK, Gupta RK, Pandey R. Tuberculous Addison's disease: Lack of normalization of adrenocortical function after antituberculous chemotherapy. Clin Endocrinol (Oxf). 1998;48(3):355-9. http://doi.org/10.1046/j.1365-2265.1998.00409.x.

12. Guo YK, Yang ZG, Li Y, Ma ES, Deng YP, Min PQ, et al. Addison's disease due to adrenal tuberculosis: Contrast-enhanced features and clinical duration correlation. Eur J Radiol. 2007;62(1):126-31. http://dx.doi.org/10.1016/j.ejrad.2006.11.025,

13. Rowińska-Zakrzewska E, Szopiński J, Remiszewski P, Szymański D, Miller P, Pawlicka L, et al. Tuberculosis in the autopsy material: Analysis of 1500 autopsies performed between 1972 and 1991 in the Institute of Tuberculosis and Chest Diseases, Warsaw, Polnad. Tuber Lung Dis. 1995;76(4):349-54. http://dx.doi.org/10.1016/S09628479(05)80035-8. 
14. Soule S. Addison's disease in Africa- A teaching hospital experience. Clin Endocrinol (Oxf). 1999;50(1):115-20. http://dx.doi.org/10.1046/ j.1365-2265.1999.00625.x.

15. Jacobi J, Schnellhardt S, Kulschewski A, Amann KU, Kuefner MA, Eckardt KU, et al. An unusual case of hyponatraemia. Nephrol Dial Transplant. 2010;25(3):998-1001. http://dx.doi.org/10.1093/ndt/gfp698.

16. Dorin RI, Qualls CR, Crapo LM. Diagnosis of adrenal insufficiency. Ann Intern Med. 2003; 139(3):194-204. http://dx.doi.org/10.7326/00034819-139-3-200308050-00017.

17. Upadhyay J, Sudhindra P, Abraham G, Trivedi N. Tuberculosis of the adrenal gland: A case report and review of the literature of infections of the adrenal glands. Int J Endocrinol. 2014;2014:876037. http://dx.doi.org/10.1155/2014/876037.
18. Wise GJ, Marella VK. Genitourinary manifestations of tuberculosis. Urol Clin North Am. 2003;30(1):111-21. PMID: 12580563.

19. Kelestimur F. Recovery of adrenocortical function following treatment of tuberculous Addison's disease. Postgrad Med J. 1993;69(816):832-4. http://dx.doi.org/10.1136/pgmj.69.816.832.

20. Visweswaran RK, Bhat S. Tuberculosis of the urinary tract. In: Comprehensive Clinical Nephrology. J Floege, RJ Johnson, J Feehally, eds. 4th ed. St. Louis: Elsevier Saunders, 2010.

21. Dąbrowska A, Tarach J, Prystupa A, Kurowska M. Addison's disease due to tuberculosis of the adrenal glands. Journal of Pre-Clin Clin Res. 2012;6(2):88-92.

22. Bancos I, Hahner S, Tomlinson J, Arlt W. Diagnosis and management of adrenal insufficiency. Lancet Diabetes Endocrinol. 2015;3(3):216-26. http://dx.doi.org/10.1016/S2213-8587(14)70142-1.

Authors are required to accomplish, sign and submit scanned copies of the JAFES Author Form consisting of: (1) the Authorship Certification that the manuscript has been read and approved by all authors, and that the requirements for authorship have been met by each author, (2) the Author Declaration that the article represents original material that is not being considered for publication or has not been published or accepted for publication elsewhere, (3) the Statement of Copyright Transfer[accepted manuscripts become the permanent property of the JAFES and are licensed with an Attribution-Share Alike-Non-Commercial Creative Commons License. Articles may be shared and adapted for non-commercial purposes as long as they are properly cited], (4) the Statement of Disclosure that there are no financial or other relationships that might lead to a conflict of interest. For Original Articles involving human participants, authors are required to submit a scanned copy of the Ethics Review Approval of their research. For manuscripts reporting data from studies involving animals, authors are required to submit a scanned copy of the Institutional Animal Care and Use Committee approval. For Case Reports or Series, and Images in Endocrinology, consent forms, are required for the publication of information about patients; otherwise, authors declared that all means have been exhausted for securing such consent. Articles and any other material published in the JAFES represent the work of the author(s) and should not be construed to reflect the opinions of the Editors or the Publisher.

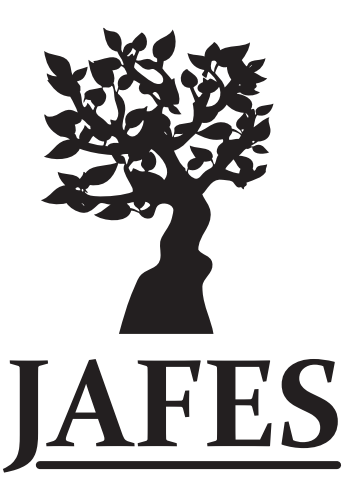

\section{Send your paper to the publication pathway. Instructions to Authors at www.ASEAN-endocrinejournal.org.}

